\title{
CRESCIMENTO RELATIVO DO CAMARÃO MACROBRACHIUM AMAZONICUM (HELLER, 1862) (DECAPODA, PALAEMONIDAE) NA SUB-BACIA DO SALGADO, CEARÁ, BRASIL
}

\author{
Alencar, D. R. ${ }^{1}$; Pitombeira, G. S. G. N. ${ }^{1}$; Correia, D. B. ${ }^{1}$; Nascimento, W. M. ${ }^{1}$; Lima, L.S. ${ }^{1}$; Lucena, I.C. ${ }^{1}$; \\ Macedo, R.S. ${ }^{1}$; Araújo, J.G. ${ }^{1}$ \& Pinheiro, A.P. ${ }^{1}$ \\ ${ }^{1}$ Universidade Regional do Cariri (URCA), Campus Pimenta, Crato, CE, \\ Laboratório de Crustáceos do Semiárido (LACRUSE). \\ *Autor correspondente: damarisalencar@hotmail.com
}

\begin{abstract}
O camarão de água doce Macrobrachium amazonicum é considerado uma espécie modelo para estudos ecológicos, devido a sua plasticidade fenotípica. A espécie foi amplamente estudada recentemente em ambientes controlados e ecossistemas costeiros da região Norte do Brasil. Contudo estudos ecológicos para regiões pouco exploradas como o semiárido nordestino podem nos revelar informações importantes acerca do desenvolvimento da espécie. Estudos de crescimento são crusciais para o conhecimento de aspectos biológicos, ecológicos, reprodutivos e evolutivos em crustáceos. Recentemente, M. amazonicum ganhou destaque ao serem classificados quatro morfotipos na estrutura social de machos, de acordo com as características morfológicas externas. Cada morfotipo representa um estágio diferente do crescimento e varia de acordo com a cor e o comprimento do quelípodo. Portanto, o objetivo do presente estudo foi analisar o crescimento relativo de machos de $M$. amazonicum provenientes de populações do semiárido nordestino. Foram analisados 120 espécimes provenientes de expedições na sub-bacia do rio Salgado referentes ao projeto "Crustáceos do Semiárido", . Os camarões foram considerados morfologicamente adultos pela presença do apêndice masculino no segundo par de pleópodes. Para a análise de crescimento relativo, a regressão alométrica $\left(\log y=\log a+b^{*} \log x\right)$ foi utilizada como variável dependente $(y)$ o comprimento do quelípodo, em resposta à variável independente $(x)$, comprimento da carapaça. Os machos apresentaram correlação significativa das variáveis morfométricas analisadas $\left(r^{2}=0,6679 ; p<0,001\right)$ e crescimento alométrico negativo do própodo em resposta ao crescimento da carapaça $(b=87192 ; p<0,001)$. A menor taxa de crescimento do própodo em relação a carapaça provavelmente resulta da disponibilidade de recursos, que pode restringir a biologia de machos $M$. amazonicum no semiárido nordestino. Dessa forma, as maiores taxas de temperatura relativa dos ecossistemas aquáticos podem acelerar o metabolismo dos machos de M. amazonicum e fazer com que os mesmos atinjam a maturidade sexual om menor tamanho morfométrico, relatando novas características morfológicas para a espécie no semiárido brasileiro. Por fim, espera-se com esse trabalho ampliar os conhecimentos sobre as interações da espécie com o ecossistema semiárido.
\end{abstract}

Palavras-chave: semiárido, alometria, Camarão da Amazônia. 